\title{
La deuda como fuerza colectiva
}

Debt as Collective Strength

\author{
Christy Thornton ${ }^{2}$ y Philip Mader ${ }^{3}$ \\ Progressive International
}

Revista Derechos en Acción ISSN 2525-1678/ e-ISSN 2525-1686

Año 6/NNo 18 Verano 2020-2021 (21 diciembre a 20 marzo), 805-815

DOl: https://doi.org/10.24215/25251678e496

Resumen: Los países y las personas pobres tienen pocas de las protecciones que tienen los ricos, pero tienen el poder de su fuerza colectiva. Los deudores del mundo pueden unirse y dejar de pagar.

Abstract: Poor countries and poor people have few of the protections the rich do, but they have the power of their collective strength. Debtors of the world can unite, and default.

No pagar las deudas, nos dicen, es fracasar, romper tus promesas, manchar tu honor personal y el de tu familia. En otros ensayos, hemos visto cómo los acreedores, las empresas

\footnotetext{
1 Este ensayo forma parte de la serie "Deuda y poder" del Proyecto de Justicia de la Deuda de la Internacional Progresista, y se encuentra disponible en inglés en el siguiente enlace: https://progressive.international/blueprint/c758f678-cdc6-40e8-a2d6-0a7c0092f10e-debtas-collective-strength/en La colección completa de la que forma parte está disponible en https://progressive.international/blueprint/606164ba-c29f-4f32-b464-50bc9b7f1a26-ablueprint-for-debt-justice/en

2 Christy Thornton es profesor asistente de sociología y estudios latinoamericanos en la Universidad Johns Hopkins, donde colabora para liderar la Iniciativa sobre América Latina en un Mundo Globalizante.

3 Philip Mader es un economista político y sociólogo económico que investiga y da clases en el Instituto de Estudios de Desarrollo, Reino Unido. Christy Thornton y Phil Mader son integrantes del Grupo de Trabajo en la Justicia de la Deuda de la Internacional Progresista.
} 
y los fondos buitre conspiran para que los deudores se sientan solos, rotos y cargados con esta sensación de fracaso moral.

Pero aunque nuestros sistemas legales castigan a algunos deudores por impagos, en realidad están preparados para permitir a otros deudores "reestructurar" sus deudas y librarse completamente de sus obligaciones. El capital es consciente de esta fuerza. En los Estados Unidos, se dice que las protecciones contra la bancarrota de las empresas, como el "Capítulo 11" del Código de Quiebras, que permite a las empresas reestructurar sus deudas, fomentan la "toma de riesgos", lo que permite a enormes empresas como General Motors, Purdue Pharma y Sears asumir deudas masivas y luego renegociarlas cuando sus apuestas no dan resultado, dejando a menudo que los/as trabajadores/as y titulares de pensiones sufran las consecuencias más duras.

Ahora estamos viendo este proceso en tiempo real. Tras la ola de quiebras empresariales de la crisis financiera de 2008, la crisis de la COVID-19 ha inspirado otra nueva. Mientras enormes empresas de países como Estados Unidos han despedido a decenas de miles de trabajadores/as, han luchado en los tribunales para asegurarse de que pueden dar lujosas bonificaciones a sus principales ejecutivos/as, mientras se preparan para reestructurar sus deudas. La Reserva Federal de Estados Unidos, por su parte, está respaldando el riesgo privado de las grandes empresas mediante la creación de fondos especiales para la compra de deuda corporativa: un caso clásico de riesgo socializado y ganancia privatizada.

Y así vemos que cuando se trata de deuda, hay un conjunto de reglas para los ricos, y otro para el resto de nosotros/as. Las protecciones como el "Capítulo 11" no se conceden ni a los países pobres que se enfrentan a crisis de deuda soberana ni a trabajadores/as comunes que se encuentran con una sobrecarga de deudas. De hecho, cuando los países y las personas pobres se retrasan en el pago de sus deudas, las "soluciones" casi siempre empeoran las cosas, dando lugar a tasas de interés 
más altas y a sistemas más onerosos de castigo y vigilancia. Desarrollar una reputación de riesgo crediticio, ya sea como individuo o como país pobre, conlleva la amenaza de perder por completo el acceso al crédito. Esta amenaza actúa como un poderoso elemento disuasorio para el impago, obligando a los países y a las personas pobres a aceptar condiciones predatorias que los encierran habitualmente en espirales interminables de endeudamiento, pobreza y desesperación.

Pero, ¿qué pasaría si le diéramos la vuelta a la pirámide?

Mientras que los países y las personas pobres tienen pocas de las protecciones que tienen las empresas ricas, sí tienen el poder de su fuerza colectiva. Aunque el "poder estructural de las finanzas" - es decir, la capacidad de los acreedores para decidir quién tiene acceso al dinero y quién no- ha aumentado, también lo ha hecho la capacidad de los deudores para movilizar su papel crucial en el sistema financiero mundial. Dicho de otro modo: a medida que las finanzas adquieren una importancia cada vez mayor en el conjunto de la economía mundial, también lo hace el poder político del rechazo de la deuda colectiva. Al reconocer su papel clave en el funcionamiento del capitalismo global, los deudores pueden reclamar por sus vidas, sus comunidades, sus países y transformar la economía global para bien.

Este ensayo examina y se inspira en las revueltas históricas de los/as deudores/as, que pueden inspirarnos y ayudarnos a construir un proyecto de justicia de la deuda basado en nuestra fuerza colectiva.

\section{El peso de la deuda}

En las últimas décadas se han producido repetidas crisis financieras ante la amenaza de impago de la deuda soberana. El anuncio de México en 1982 de que no podría seguir cumpliendo con sus obligaciones de deuda externa desencadenó una espiral de crisis de deuda cuyas reverberaciones se siguen sintiendo hoy en día. Antes de la crisis de la deuda, instituciones como 
el FMI tenían algunas palancas de influencia sobre las políticas de los países en desarrollo a través de las "condicionalidades". En otras palabras, para obtener un préstamo del FMI, los países tenían que aceptar cambios en sus políticas económicas internas - como equilibrar los presupuestos reduciendo el gasto público y limitar la oferta monetaria para luchar contra la inflación- que tenían por objetivo "estabilizar" sus economías y, al mismo tiempo, garantizar que pudieran seguir cumpliendo con sus obligaciones exteriores. Los expertos del FMI casi siempre sostenían que los problemas de los países en desarrollo se derivaban de sus políticas económicas internas, más que de su posición en el mundo en general, y aunque el FMI podía insistir en que los países en desarrollo cambiaran sus políticas, tenía pocas herramientas, y poca voluntad política, para argumentar que los países ricos debían cambiar las suyas.

Cuando México anunció en 1982 que no podía pagar los intereses de su abultada deuda - que había pasado de 4000 millones de dólares en 1970 a más de 80000 millones en 1981— la reacción de Washington reforzó aún más el papel global de las condicionalidades del FMI. Los funcionarios del gobierno de Estados Unidos se dieron cuenta de que si México dejaba de pagar, sería desastroso no sólo para México, sino para los numerosos bancos comerciales de Estados Unidos que tenían esos enormes préstamos en sus balances. No queriendo dejar que México arrastrara al sistema financiero estadounidense a la crisis, el gobierno de Estados Unidos negoció un paquete de rescate que dio paso al "ajuste estructural" de la economía mexicana. El FMI y el Banco Mundial encontraron interlocutores comprensivos en México, tecnócratas que ya habían luchado por liberalizar la economía mexicana, y el país inició así una profunda reorientación de su modelo económico, recortando el gasto público y liberalizando las normas de comercio e inversión. Las instituciones financieras internacionales siguieron entonces un modelo de ajuste estructural similar en toda la región y, de hecho, en todo el mundo en desarrollo. El resultado de las políticas que prescribieron -que se conocieron como el Consenso 
de Washington- evitó el colapso de los bancos privados, pero creó dificultades abrumadoras en toda América Latina y en el mundo en desarrollo, siendo los/as trabajadores/as quienes resultaron más afectadas por la austeridad.

Desde la crisis mexicana de 1982, los países más pobres del mundo han enviado 4,2 billones de dólares en pagos de intereses a sus acreedores del Norte Global. ${ }^{4}$ Ahora los gobiernos asumen regularmente una nueva deuda que sólo pretende permitirles seguir pagando las deudas existentes, a menudo en forma de préstamos condicionados que siguen viniendo acompañados de exigencias de recortes presupuestarios, austeridad y desmantelamiento de las instituciones democráticas, como el caso de Ecuador que en 2020 quedó nuevamente en las manos del FMI. ${ }^{5}$ Y el miedo a perder el acceso al capital necesario para el desarrollo mantiene a muchos países pobres a raya, ya que los países más poderosos del mundo y las mayores instituciones financieras se confabulan para garantizar que los países que amenazan con incumplir sus obligaciones sean castigados con la amenaza de cortarles el crédito por completo.

No siempre ha sido así. En épocas anteriores, los Estados incumplían con frecuencia sus deudas, ${ }^{6}$ poniendo a un acreedor frente a otro o renegociando la deuda por céntimos de dólar. Y algunos Estados querían ir aún más lejos, como ocurrió en un caso durante la década de 1930, durante la Gran Depresión. El gobierno mexicano ya se enfrentaba a la ira de los acreedores y de los gobiernos poderosos desde hacía décadas, tras haber dejado de pagar su deuda externa durante la Revolución Mexicana. Grupos de banqueros y tenedores de bonos se unieron

\footnotetext{
4 Jerome Roos, Why Not Default? The Political Economy of Sovereign Debt, Princeton University Press, 2019.

5 Internacional Progresista, "For the Sovereignty of the Ecuadorian People", 29 de julio de 2020.

6 Eric Toussaint, Nathan Legrand y Christina Laskaridis, "Historical Perspectives on Current Struggles against Illegitimate Debt", en Philip Mader, Daniel Mertens y Natascha van der Zwan (eds.), The Routledge International Handbook of Financialization, Routledge, 2020.
} 
para formar cárteles de acreedores y asegurarse de que nadie le prestara a México hasta que pagara sus deudas pendientes. En respuesta, el Ministro de Asuntos Exteriores mexicano, José Manual Puig Casaraunc, expuso en 1933 una visión del poder colectivo de los deudores que resuena hasta hoy. ${ }^{7}$ Abogó por reconocer la necesaria interdependencia que implica la deuda: el crédito es una “ecuación' de al menos dos términos”, argumentó, y "exactamente el mismo servicio es prestado por la parte que concede el préstamo así como por la que lo toma”. Es decir, al igual que el deudor necesita los fondos del acreedor, este necesita una salida productiva para su capital excedente: el prestatario. Sin ese prestatario dispuesto a tomar sus fondos y devolverlos con intereses, los acreedores no ganarían dinero.

Pero el sistema financiero internacional no había reconocido el papel crucial que desempeñan los prestatarios en el funcionamiento del sistema capitalista mundial. Por lo tanto, Puig abogó por una "nueva concepción jurídica y filosófica del crédito", que reconociera el papel central que desempeñan los deudores, y en la que estos, colectivamente, reconocieran su propio poder dentro del sistema. Su visión de una distribución democrática del crédito, en la que las economías y sociedades de los deudores no estuvieran subordinadas a los motivos de lucro de las instituciones financieras más grandes y poderosas, no se hizo realidad en la década de 1930 . Pero su llamamiento a reconocer el papel sistémicamente crucial de los deudores para el funcionamiento de la economía mundial sigue resonando, y puede orientar el poder colectivo de los deudores, tanto individuales como nacionales.

\section{Cuando los deudores se vuelven rebeldes}

Cuando los Estados amenazan con incumplir sus obligaciones, esto alcanza los titulares periodísticos. Pero el impago de

\footnotetext{
7 Christy Thornton, Revolution in Development Mexico and the Governance of the Global Economy, University of California Press, 2021.
} 
las hipotecas o de las tarjetas de crédito por parte de los particulares apenas es noticia, excepto cuando muchos se vuelvan morosos a la vez: entonces, pueden hacer temblar los cimientos morales y económicos del sistema financiero.

Por supuesto, el camino que va de la resistencia del deudor a su triunfo está lejos de ser seguro. Cuando millones de prestatarios/as estadounidenses de alto riesgo incumplieron simultáneamente sus hipotecas, fueron los prestamistas - no los/as deudores/as - los/as que lograron imponer su poder. Mientras el gobierno estadounidense rescataba a los prestamistas de su quiebra, estos mismos prestamistas iniciaron procedimientos de ejecución hipotecaria contra 1,3 millones de propiedades en 2007, 2,3 millones en 2008 y 2,8 millones en 2009. Millones de personas - tanto prestatarios/as de bajo riesgo como de alto riesgo, y sus familias- perdieron sus casas. ${ }^{8}$ Las minorías y las mujeres fueron las que más sufrieron.

Sin embargo, la historia financiera reciente también está llena de ejemplos de prestatarios que renegocian o rechazan colectivamente obligaciones de pago que ya no consideran válidas. Tomemos el caso de los y las ciudadanas de Islandia, que repudiaron las deudas de los bancos masivamente sobreapalancados del país. La historia oficial registró estos acontecimientos entre 2008 y 2011 como la "crisis financiera islandesa", aunque en realidad fue una revuelta de deudores a nivel nacional y una revolución política. Los bancos privados islandeses habían ofrecido cuentas de ahorro extremadamente lucrativas a inversores en el extranjero y acumularon deudas externas impagables por valor de más de cinco veces el PIB del país. El gobierno del Reino Unido invocó la legislación antiterrorista para obligar al gobierno de Islandia a pagar. Pero los y las ciudadanas islandeses rechazaron dos veces el plan de reembolso y destituyeron a su gobierno en la "revolución

8 Fernando Ferreira y Joseph Gyourko, "A New Look at the U.S. Foreclosure Crisis: Panel Data Evidence of Prime and Subprime Borrowers from 1997 to 2012", NBER Working Paper 21261, 2015. 
de los utensilios de cocina", 9 que dio lugar a una Asamblea Ciudadana para debatir cambios en la Constitución de Islandia. Los banqueros y los políticos fueron juzgados y condenados a penas de prisión, y la mayor parte de la deuda fue condonada.

El ejemplo de Islandia puede parecer difícil de emular para otros. Sin embargo, algunos de los pueblos más pobres del mundo también han demostrado el poder que tienen los deudores cuando actúan colectivamente. Empezando por Bolivia en el año 2000, una oleada de revueltas de deudores/as ha barrido el sector de las microfinanzas a nivel mundial, ${ }^{10}$ con millones de personas pobres en Bosnia-Herzegovina (2008), Nicaragua (2008-9), India (2010-11) y Marruecos (2011-13) protestando contra demandas irrazonables, negándose a pagar y forzando la renegociación y la cancelación de la deuda. En muchos casos, fue la excesiva fuerza utilizada por las instituciones de microfinanzas lo que desencadenó la indignación y la solidaridad popular entre los microprestatarios como artesanos/as, vendedores/as ambulantes y pequeños/as agricultores/as, que de otro modo probablemente no estarían organizados. Esto catalizó primero las demandas de renegociación de las condiciones de los préstamos, y luego el rechazo rotundo.

En Nicaragua, tras la detención de algunos deudores, decenas de miles exigieron su liberación y mejores condiciones. Se formó un movimiento bajo el sencillo lema de "No Pago". Después de que los enfrentamientos con las autoridades locales hicieran que se quemaran las oficinas de microfinanzas, los políticos tomaron nota y los representantes de "No Pago" lograron presentar dos proyectos de ley en el parlamento, obligando a los prestamistas a renegociar plazos más largos y tipos de interés más bajos. En la India, después de que los agentes de

\footnotetext{
9 Thorvaldur Gylfason, "Democracy on ice: a post-mortem of the Icelandic constitution", Open Democracy, 19 de junio de 2013.

10 Governance across borders, "'We are at the end of our tether!' What African Women are trying to tell the Microfinance Industry", (20 de diciembre de 2017). Disponible en: https:// governancexborders.com/2017/12/20/we-are-at-the-end-of-our-tether/
} 
crédito coaccionaran a decenas de deudores hasta el punto que se suicidaron (los prestamistas de microfinanzas tenían en su mira puesta en sus seguros de vida), las protestas y la violencia estallaron en todo Andhra Pradesh, ${ }^{11}$ obligando al gobierno estatal a decretar el cese de toda actividad de microfinanzas. Cuando los agentes de crédito volvieron, se encontraron con prestatarios colectivamente hostiles y poco dispuestos a pagar, y hubo que cancelar más de mil millones de dólares en préstamos. En el sur pobre de Marruecos, durante la Primavera Árabe, un movimiento dirigido por mujeres, Victimes du Microcrédit, organizó la resistencia contra el cobro de préstamos y cerró las oficinas de microfinanzas. Sin embargo, el gobierno marroquí se confabuló con los prestamistas y reprimió el movimiento.

Estos ejemplos sirven para ilustrar cómo incluso algunos/as de los/as deudores/as más pobres del mundo han ejercido con éxito el poder colectivo. Por supuesto, las revueltas de los deudores pueden ser complicadas y estar llenas de riesgos políticos: No Pago fue cooptado en gran medida por el gobierno de Daniel Ortega; los gigantes de la microfinanzas de Andhra Pradesh simplemente se trasladaron a otros Estados de la India; y las mujeres que lideraban Victimes du Microcrédit fueron condenadas a prisión. Pero expresan una creciente conciencia de deudor en torno a lo que EP Thompson denominó "economía moral": una insistencia fundamental y universal por parte de la gente corriente en obtener resultados de mercado justos, y su voluntad de emprender acciones directas para conseguirlos.

\section{Convertirse en una amenaza sistémica}

En los siglos XVIII y XIX, la economía moral de la clase trabajadora dio lugar al movimiento sindical. En el XXI, ¿podría la desobediencia de los deudores convertirse en la base de un

\footnotetext{
11 Philip Mader, "Rise and Fall of Microfinance in India: The Andhra Pradesh Crisis in Perspective", 1-2 Strategic Change, 2013, Vol. 22, 47-66.
} 
movimiento global? Los actores del establishment suelen presentar a los deudores desafiantes como campesinos ignorantes, ludistas financieros o peones políticos populistas. Una política progresista de la deuda invierte la condescendencia, revela la dinámica de clase y ayuda a construir el poder colectivo de los deudores que no pueden o no quieren pagar.

La conciencia de clase de los deudores y el consenso para la acción no serán fáciles de construir. Las deudas a menudo se esconden en la vergüenza y están impregnadas de obligaciones morales ("debes pagar lo que prometiste"). Pero tanto si se expresa en Estados Unidos ("el 1 \% contra el $99 \%$ ") o en Nicaragua ("usureros contra campesinos"), la gente tiene una conciencia subjetiva de las relaciones objetivas de la deuda. En la cúspide de las cadenas de valor financieras globales - ya sean construidas sobre hipotecas o préstamos de microfinanzas- se sitúan en última instancia los acumuladores de capital más ricos del mundo, mientras que en la base se sitúan los/as deudores/as, los y las ciudadanas que pueden acatar o dejar de seguir el juego. Cuanto mayor sea el colectivo, mayor será su poder cuando lo utilicen. Los mercados financieros dependen de flujos de pagos regulares, y el poder de interrumpirlos hace que los colectivos de deudores sean una poderosa amenaza sistémica para el capitalismo financiarizado.

\section{Internacionalismo de los y las deudoras}

Dada la estructura global de los regímenes de deuda, el internacionalismo es indispensable. Los movimientos de los deudores formados a nivel nacional o subnacional no deben luchar solos. La solidaridad internacional fue fundamental para el éxito de Islandia, por ejemplo, ya que un público mundial observó con simpatía y respaldó a Islandia contra las amenazas británicas. Las protestas de los microdeudores no han captado tanta atención mundial. Una prueba crucial será la inminente crisis de la microdeuda en Camboya: los/as camboyanos/as son 
"la mayor clase de prestatarios de microcréditos del mundo", ${ }^{12}$ y hasta 2,2 millones de personas corren el riesgo de perder sus tierras que fueron ofrecidas como garantía. ${ }^{13}$ ¿Las fuerzas progresistas los/as apoyarán?

La fuerza de los prestamistas es visible en todas partes. Los/as deudores/as apenas están descubriendo la suya. Los/as deudores/as pueden ejercer un poder colectivo cuando:

- ponen de manifiesto la interdependencia de la relación de la deuda;

- toman conciencia de los intereses compartidos y se organizan;

- son capaces de combinar las demandas específicas de cambio con las amenazas de negarse a pagar; $y$

- trabajan en solidaridad con movimientos progresistas más amplios.

Un movimiento internacional progresista puede ayudar a los/as deudores/as desafiantes a llevar la lucha a los palacios de las finanzas. Pueden reunir a los movimientos de deudores, codesarrollar estrategias de acción y traducir las demandas particulares en un lenguaje político universal, como la democratización del impago. Cuando las deudas no sirven para nada más que para permitir una mayor acumulación de riqueza privada, declararlas ilegítimas golpea el corazón del capitalismo financiero, que resulta ser excepcionalmente frágil y dependiente del apoyo político frente a las amenazas sistémicas. Por lo tanto, las victorias políticas tácticas, como la condonación de la deuda, una mayor protección de los/as consumidores/as y la responsabilidad financiera son pasos hacia un premio mayor: la propiedad solidaria y libre de deudas de los medios de producción.

\footnotetext{
12 Sangeetha Amarthalingam, "Will the financial sector continue to buck Covid-19 headwinds?", The Phnom Penh Post, 1 de octubre de 2020.

13 Phillip Mader, "Microfinanced land-grabs and abuses in Cambodia are no surprise", Institute of Development Studies, 6 de septiembre de 2019.
} 